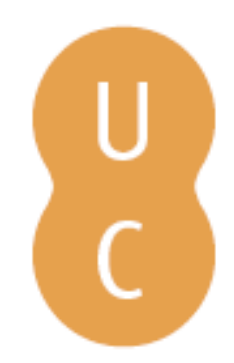

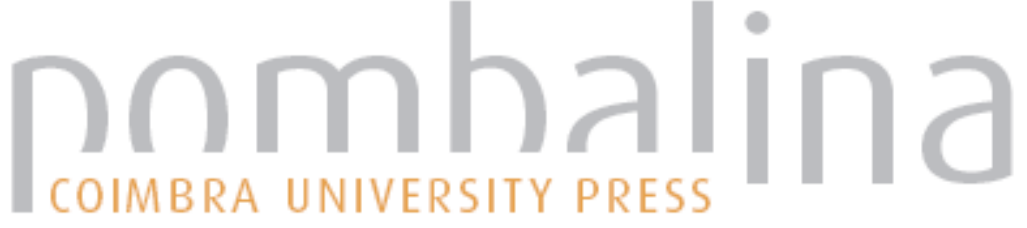

\section{Aquisição de dados tridimensionais em ambiente SIG}

Autor(es): $\quad$ Franco, António Sousa; Marques, Ana; Dias, José

Publicado por: Imprensa da Universidade de Coimbra

URL

persistente: URI:http://hdl.handle.net/10316.2/37063

DOI: $\quad$ DOI:http://dx.doi.org/10.14195/978-989-26-0983-6_10

Accessed : $\quad$ 26-Apr-2023 14:57:52

A navegação consulta e descarregamento dos títulos inseridos nas Bibliotecas Digitais UC Digitalis, UC Pombalina e UC Impactum, pressupõem a aceitação plena e sem reservas dos Termos e Condições de Uso destas Bibliotecas Digitais, disponíveis em https://digitalis.uc.pt/pt-pt/termos.

Conforme exposto nos referidos Termos e Condições de Uso, o descarregamento de títulos de acesso restrito requer uma licença válida de autorização devendo o utilizador aceder ao(s) documento(s) a partir de um endereço de IP da instituição detentora da supramencionada licença.

Ao utilizador é apenas permitido o descarregamento para uso pessoal, pelo que o emprego do(s) título(s) descarregado(s) para outro fim, designadamente comercial, carece de autorização do respetivo autor ou editor da obra.

Na medida em que todas as obras da UC Digitalis se encontram protegidas pelo Código do Direito de Autor e Direitos Conexos e demais legislação aplicável, toda a cópia, parcial ou total, deste documento, nos casos em que é legalmente admitida, deverá conter ou fazer-se acompanhar por este aviso. 


\section{$\forall$ \\ TAS DAS I JORNADAS LUSÓFONAS DE CIÊNCIAS E TECNOLOGIAS DE INFORMAÇÃO GEOGRÁFICA}

Editores

José Gomes dos Santos

Cidália Fonte

Rui Ferreira de Figueiredo

Alberto Cardoso

Gil Gonçalves

José Paulo Almeida

Sara Baptista 


\section{A RTIG O 10 \\ AQUISIÇÃO DE DADOS TRIDIMENSIONAIS EM AMBIENTE SIG}

FRANCO, António Sousa ${ }^{1}$; MARQUES, Ana ${ }^{2}$ E DIAS, José

Instituto Geográfico do exército

Av. Alfredo Bensaúde, 1849-014 Lisboa

1 afranco@igeoe.pt

${ }^{2}$ marques.ana.t.n@gmail.com

\section{RESUMO}

O processo de produção cartográfica da Carta Militar, Série M888, escala 1:25 000 do Instituto Geográfico do Exército (IGeoE) consiste numa sequência de passos de elevada complexidade mas que são normalmente abordados de forma autónoma sendo a aquisição de informação efetuada por processos fotogramétricos a primeira dessas etapas. Tendo como objetivo tirar partido das potencialidades de um Sistema de Informação Geográfica (SIG) para a produção cartográfica foi precisamente neste primeiro passo que esse conceito foi introduzido no IGeoE.

Devido às implicações que tal alteração representa numa Cadeia de Produção que tem vindo ao longo dos tempos a ser adaptada e aperfeiçoada e atendendo ao elevado investimento que representa é necessário que a sua implementação seja feita de forma faseada.

Pretende-se, portanto, com este artigo abordar de forma resumida a atualização do processo de aquisição de dados em ambiente estereoscópico recorrendo a Sistemas de informação geográfica, salientando o tipo e o formato de dados que assim são obtidos, assim como os diversos processos que visam tornar essa informação o mais coerente possível com a realidade existente no terreno. 


\title{
PALAVRAS-CHAVE
}

SIG, Fotogrametria, Cartografia, Estereoscopia, Base de dados.

\section{ACQUISITION OF 3D DATA IN GIS ENVIRONMENT}

\begin{abstract}
The process of cartographic production of M888 military map of the Army Geographic Institute (IGeoE) at scale 1:25 000, consists in a high complexity sequence of steps which are usually discussed separately. Being the acquisition of spatial information from stereoscopic pairs the first of these steps, it was precisely where has been introduced the concept of using Geographic Information Systems (GIS) to produce spatial data.

Due to the implications that this change represents for a system that has over the years being adjusted and tuned, given the high investment so that it becomes feasible it is necessary for its implementation be done in a phased manner.

Therefore, we intend to approach with this article in brief the process of adapting the methods of acquiring stereoscopic environment, using GIS, emphasizing the type and format of data that are obtained, and the various processes that aim to make this information as consistent as possible with the existing reality on the ground.
\end{abstract}

KEYWORDS

GIS, Photogrammetry, Cartography, Stereoscopy, Data base

\section{INTRODUÇÃo}

O IGeoE tem vindo ao longo dos tempos a garantir a cobertura cartográfica à escala 1:25 000 de todo o território nacional. Tal cartografia é criada tendo por base informação geográfica adquirida tanto com a tecnologia como com os conhecimentos técnicos mais avançados disponíveis à época em que tal é feito. Ao longo dos tempos os processos de aquisição de informação têm vindo a ser desenvolvidos, adaptados e melhorados de forma a possibilitar ao IGeoE a resposta a necessidades de redução de custos e de frequência de atualização cada vez mais exigentes. Tal acompanhamento tecnológico só se torna possível dando um peso destacado à componente de investigação e desenvolvimento do sistema de produção cartográfica já que se torna extremamente complexo o acompanhamento de uma evolução tecnológica em constante aceleração. 
É neste contexto que surge o projeto SIG3D, que, apoiado pelo Centro de Investigação da Academia Militar (CINAMIL) visa a introdução do conceito de bases de dados geográficas no processo de produção cartográfica do IGeoE desde a aquisição na Secção de Fotogrametria. Tendo esse tema já sido descrito ao pormenor em Dias et al. (2011) este artigo pretende dar a conhecer o desenvolvimento do processo desde então, assim como uma abordagem dos resultados que se têm obtido e dos que se prevê vir a obter, dando uma ideia de algumas das mais-valias que tal alteração poderá ter num processo, único, de produção cartográfica como é o da Carta Militar à escala 1:25 000 do IGeoE.

\section{O CICLO DE PROdUÇÃo CARTOGRÁficA No IGEOE}

A aquisição de informação tridimensional por métodos fotogramétricos é o primeiro processo assim como o que exige mais recursos de uma cadeia de produção cartográfica modelada pelos requisitos de qualidade que sempre lhe foram imputados. O respetivo resultado consiste em ficheiros com informação georreferenciada que, após uma primeira validação temática e geométrica ainda em ambiente estereoscópico, são sujeitos a um processo de completagem por equipas de topografia onde a informação é confrontada com a realidade do terreno. Segue-se então um conjunto de processos de validação de conteúdo, geométrica e topológica, para finalmente ser inserida na Base de Dados Geográfica do Instituto.

A principal finalidade da Base de Dados Geográfica é a produção da cartografia impressa 1:25 000 sendo este o produto mais emblemático do IGeoE assim como uma referência a nível nacional e internacional. No entanto, tendo em conta a sua abrangência e nível de pormenor, esta é cada vez mais disponibilizada para outro tipo de fins tendo, por esse motivo, uma elevada importância a qualidade com que essa informação é apresentada tanto a nível geométrico como de classificação ou a nível de consistência topológica.

Para efeitos de cartografia militar, o passo seguinte consiste na edição da informação que se encontra na Base de Dados Geográfica (Figura 1), transformando-a e adaptando-a, criando desta forma uma Base de Dados 
Cartográfica destinada à representação do terreno em duas dimensões. Aqui a informação é simbolizada e editada com o objetivo de possibilitar uma melhor visualização e interpretação à escala que se destina. Posteriormente, essa mesma Base de Dados Cartográfica é sujeita a diversos processos de controlo de qualidade, findos os quais, os dados geográficos voltarão a ser editados até estar garantida mais uma vez a qualidade suficiente para o passo seguinte, a impressão. No entanto, se a finalidade da informação for outra que não a cartografia, é importante garantir uma consistência topológica, o que se consegue através de um conjunto de processamentos que corrigem erros topológicos garantindo assim que a Base de Dados Geográfica a tenha. Tendo a noção de que até aqui a informação era adquirida em formato DGN, com o qual eram bastante complexos esse tipo de processamentos, é precisamente neste ponto que se pretende e espera vir a tirar grande partido do conceito de base de dados na cadeia de produção.

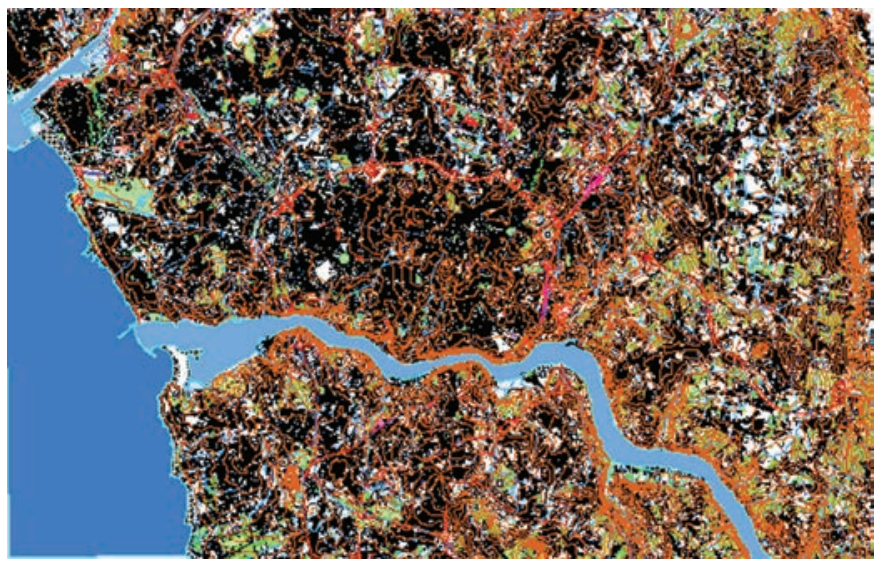

Figura 1 - Informação adquirida respeitante a uma folha da carta militar à escala 1:25000 do IGeoE

\section{EVOLUÇÃo DO PROCESSO DE AQUISIÇÃo FOTOGRAMÉTRICA}

\subsection{Estado inicial}

Anteriormente à introdução do conceito de Bases de Dados Geográficos no processo de restituição fotogramétrica era utilizada uma metodologia 
baseada essencialmente em software CAD (Computer Assisted Design), onde a informação era registada em ficheiros com o formato DGN (design), formato proprietário do Microstation, da Bentley, distinguindo cada um dos objetos pela diferenciação dos respetivos atributos (Cor, nível, tipo e espessura). A cada tema existente no catálogo de elementos era atribuído um código composto pela informação respeitante a esses atributos não existindo dois iguais. Eram então utilizadas tabelas em ficheiros de texto, que continham esses códigos, às quais o software recorria para identificar o tipo de objeto com que estava a lidar.

Tal processo era assente em diversas aplicações MDL que foram desenvolvidas, algumas delas no IGeoE, ao longo dos tempos e que executavam, de forma precisa e confiável, todas as tarefas necessárias à cadeia de produção. No entanto, o processo mostrava-se limitado na manipulação da informação altimétrica fora do ambiente estereoscópico e à reduzida análise espacial permitida pelo ambiente CAD.

No que respeita ao armazenamento da informação, esta era guardada em ficheiros DGN contendo, cada um deles, a informação da respetiva folha da Carta Militar M888 à escala 1:25 000. Com uma área de 160 $\mathrm{Km}^{2}$ e por ser considerada a unidade mínima de trabalho na Cadeia de Produção coincidia com a área de trabalho atribuída a cada operador e assim prosseguia ao longo da cadeia até ser armazenada num diretório que contém todas as folhas do território nacional dessa mesma Série.

\subsection{Fase intermédia}

A primeira fase de implementação do projeto SIG 3D consistiu essencialmente na alteração do software de restituição para um que fosse diretamente compatível com um SIG. Tendo sido escolhido o "Summit Evolution” desenvolvido pela DAT/EM Systems International, o qual é inteiramente conciliável com o ArcGIS sendo assim possível, sem alterar significativamente o processo de restituição para o operador, incutir este novo conceito na aquisição.

Sendo a restituição fotogramétrica o início da cadeia de produção cartográfica, a aquisição de informação passa a ser efetuada já em formato 
SIG, salvaguardando-se a possibilidade de em qualquer outra fase da cadeia esta se converter para DGN de forma a possibilitar a utilização do processo antigo ainda em utilização até que a restante cadeia de produção seja adaptada, o que deve acontecer de forma gradual.

A unidade trabalho continua a ser a folha da carta M888, $160 \mathrm{Km}^{2}$, sendo no entanto a informação restituída já em formato SIG diretamente para uma GeoDataBase (GDB). Se para o operador a diferença é mínima, para efeitos de qualidade da informação nota-se um elevado ganho, já que se passa a tirar partido das capacidades que um sistema deste tipo pode apresentar, análise e capacidade de correção topológica, possibilidade de análise espacial e principalmente a utilização das inúmeras ferramentas de geoprocessamento. Sendo esta uma solução temporária que permite a adaptação de todo o processo de aquisição de informação sem que a produtividade seja afetada significativamente foi para o efeito utilizada uma GDB que continha uma Feature Class (FC) para armazenar cada um dos objetos pertencentes ao catálogo de elementos da Carta Militar M888 do IGeoE. Esta solução tem o inconveniente de não concordar com o conceito de Base de Dados, já que por exemplo uma estrada larga será um tipo de objeto diferente de uma estrada estreita e não o mesmo objeto com um atributo diferente, o mesmo acontecendo com todos os outros elementos da referida carta o que faz com que a GDB tenha aproximadamente 270 tabelas diferentes. Também o processo de completagem já é efetuado em ambiente SIG, permitindo integrar o Cadastro Militar ${ }^{1}$ na mesma estrutura de dados da restante informação.

\subsection{Estado final desejado}

Para se conseguir tirar o máximo partido de uma base de dados que contenha uma tão elevada quantidade de informação é fundamental a utilização de uma estrutura correta. Por esse motivo procedeu-se à modelação da Base de Dados Geográfica a utilizar na produção havendo a necessidade de estudar a fundo cada um dos objetos que ela tenha de conter, diminuindo drasticamente o número de FC e identificando

\footnotetext{
${ }^{1}$ Cadastro Militar - Conjunto de atributos alfanuméricos, de interesse militar, que caracterizam alguns elementos da Carta Militar.
} 
tipos específicos de objetos através de atributos, mantendo a essência da Carta Militar. Desta forma, o peso da informação, para efeitos de armazenamento, será muito menor em relação ao método inicialmente utilizado durante a fase de testes. Essa solução permite a inclusão da informação referente a todo o território nacional numa única Base de Dados Geográfica multiutilizador armazenada num servidor, que pode ser acedida para efeitos de edição ou atualização em qualquer altura e por qualquer operador desde que, para tal, tenha permissões. Além de ter todos os temas concentrados e disponíveis numa única base de dados com ligações topológicas garantidas a três dimensões, poderão ser gerados novos produtos como por exemplo, redes viárias ou hidrográficas a três dimensões que abranjam todo o território nacional e onde todos os objetos estejam interligados entre si.

\section{INFORMAÇÃo GEOGRÁFICA ADQUIRIDA}

De forma a garantir a normalização da informação adquirida por cada um dos operadores na Secção de Fotogrametria foi criado um Guia de Extração, uma evolução das Normas de Aquisição já utilizadas no IGeoE face a adaptação do processo de aquisição de dados da Carta Militar. Este documento define de forma clara o modo como cada operador deve extrair a informação de cada par estereoscópico, assim como o método a utilizar, minimizando erros de interpretação assim como a aquisição de informação desnecessária ou a sua incorreta classificação.

A informação adquirida é integrada em cada um dos seguintes temas: vias de comunicação; hidrografia; construções; altimetria ou vegetação, os quais, acrescentando os limites e a toponímia, que têm outros métodos de aquisição, constituem os temas da nova Base de Dados Geográfica tal como apresentado na Figura 2. São portanto vários os temas adquiridos em ambiente estereoscópico, tendo por sua vez cada um deles uma série de entidades diferentes que na base de dados passarão a ser distinguidos por diversos atributos. Por exemplo, no tema vias de comunicação será criado o subtipo estrada e outro subtipo caminho pertencentes à mesma FC e podendo ainda cada um conter elementos distinguidos através de 
uma atributo (larga ou estreita no caso das estradas e carreteiro ou pé posto no caso dos caminhos) distinguindo desta forma o que anteriormente pertencia a diferentes tabelas da base de dados.

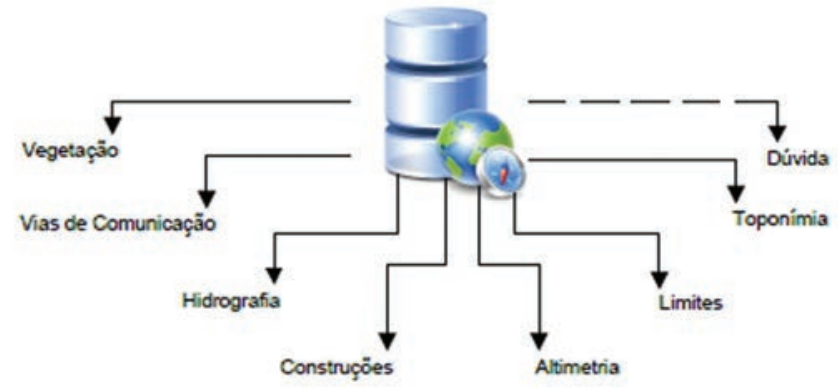

Figura 2 - Estrutura da nova base de dados geográfica a utilizar pela aquisição

Tendo em conta a fase em que o processo se encontra, onde já estão a ser utilizadas para aquisição de informação bases de dados com todas as suas potencialidades, vão sendo encontradas para cada um dos diversos temas situações que anteriormente não eram detetados ou que, se o eram, podiam ser resolvidos com recurso a aplicações que já não são compatíveis com as ferramentas em uso. Assim sendo, é necessário criar vários processos de validação de dados pelo operador, o que é conseguido com recurso a ferramentas de topologia ou de geoprocessamento automático, garantindo uma melhor qualidade nos dados imediatamente após a aquisição na Secção de Fotogrametria. Este é no entanto um processo moroso que muitas vezes depende de parâmetros que podem variar de folha para folha e que levam em consideração o tipo de geografia que esta apresenta. Dando como exemplo uma rede viária composta por diferentes tipos de vias de comunicação onde, por possível falha do operador, determinadas ligações não tenham o valor de cota coincidente. Neste caso onde visualmente existe uma ligação entre os diferentes troços, como têm diferentes valores de cota o software não considerará tal junção passando a haver uma falha nessa rede (Figura 3). Tal facto poderá facilmente ser identificado e corrigido com ferramentas de topologia, dando assim garantias de que a informação final se encontrará 
no formato correto.

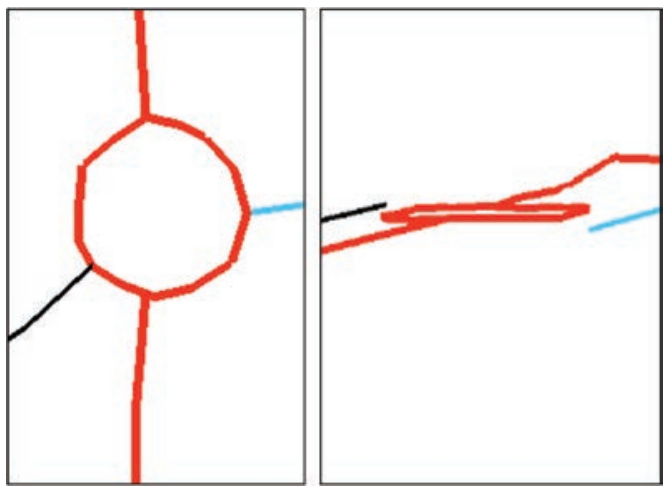

Figura 3 - Ligação de diversas vias visualizadas em 2D e em 3D

\section{ATUALIZAÇÃo VS RESTITUIÇÃo DE RAIZ}

Uma outra questão que se coloca no projeto SIG3D é, até que ponto, se pode considerar uma atualização de informação de anteriores versões de cada folha. Tendo em conta as 632 folhas da carta militar à escala 1:25 000 só em Portugal Continental são, em média, publicadas 35 folhas, Série M888, por ano, valor que não permite ter o grau de atualização desejável face à importância desta informação para o País. Considerando o período de tempo, é elevada a necessidade de atualização face às alterações introduzidas na superfície terrestre pela ação humana. Se em temas como a altimetria ou a hidrografia, que praticamente não sofrem alterações a quantidade de informação a atualizar é reduzida já a vegetação, pelo contrário, é totalmente modificada. Os restantes temas obrigam uma abordagem mais cuidadosa no momento da sua atualização. No que diz respeito a construções; rede viária e edifícios num elevado número de casos é necessária a sensibilidade por parte do operador sobre o possível aproveitamento dos dados existentes na versão anterior sendo obrigado a decidir acerca da opção a tomar (manter/corrigir/apagar ou fazer de novo) tornando-se mais simples e mais rápida a aquisição total do objeto. Por outro lado, a evolução tecnológica dos últimos anos permite uma 
exatidão posicional dos dados adquiridos substancialmente superior ao que era possível em versões anteriores, o que complica o processo de decisão. Dependendo sempre da escala a que se pretende representar, tal como se pode verificar na Figura 4, o facto de se assumir uma discrepância em dados referentes ao mesmo objeto mas em edições diferentes poderá representar uma enorme redução no tempo de trabalho de cada folha, significando isso obviamente uma redução do ciclo de atualização assim como uma redução de custos a ela associados.

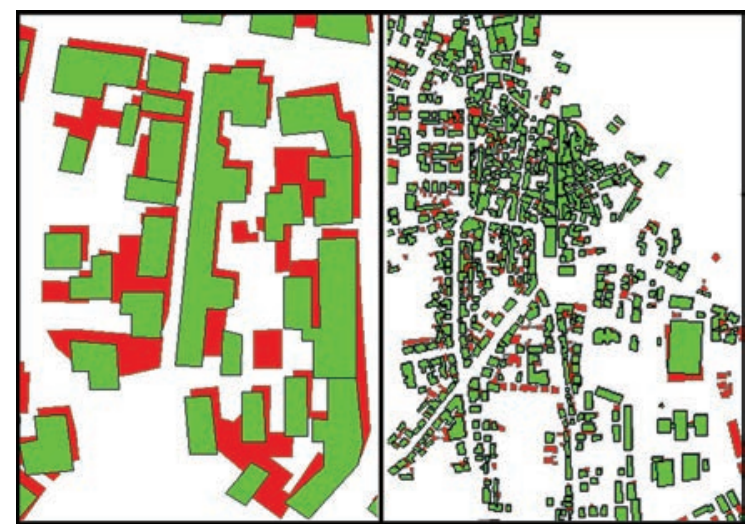

Figura 4 - Comparação da versão de 2001 (a verde) com a versão de 2013 (vermelho) da informação adquirida por métodos fotogramétricos e em diferentes escalas

\section{CONCLUSÕES}

Sendo este um projeto de cariz prático, a decorrer na Secção de Fotogrametria do IGeoE que se encontra em fase de implementação na sua cadeia de produção cartográfica é difícil retirar conclusões fundamentadas dos seus resultados já que ao nível da aquisição ainda muito se encontra por desenvolver e as alterações já efetivadas implicam uma alteração na forma de trabalho do operador. Por esta razão, os resultados a que se tem chegado são obviamente enganadores em relação às potencialidades que a base de dados pode apresentar na cadeia de produção cartográfica, até porque será nas fases de validação e edição que estas se vão fazer sentir muito mais. O facto é que a informação que é restituída, passa a ter uma consistência topológica muito maior, face aos métodos anteriores, o que é conseguido de forma natural com a utilização dos novos softwares e 
por automatismos por ele disponibilizados. Desta forma não se terá de recorrer a aplicações externas e os posteriores processos de validação serão bastante simplificados. Devido à possibilidade de relacionamento entre os diferentes tipos de objetos, será também possível automatizar parcialmente diversos processos de edição para representação cartográfica.

Por estes motivos, é consensual a opinião de que este é um passo incontornável para a simplificação e aperfeiçoamento de todo o processo de produção cartográfica no IGeoE, de forma a maximizar exponencialmente os recursos que esta instituição dispõe com o objetivo de produzir informação georreferenciada.

\section{BIBLIOGRAFIA}

DIAS, Rui; MARQUES, Ana; DIAS, José (2011) - "Aquisição de Dados em SIG3D no IGeoE”. Conferencia Nacional de Cartografia e Geodesia. Texto não publicado 
Série Documentos

Imprensa da Universidade de Coimbra

Coimbra University Press

2015

- U M

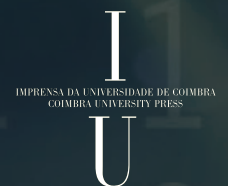

